\title{
Hydrogen Permeability of Nitrided Stainless Steel ${ }^{*}$
}

\author{
Takashi WATANABE, Teruya TANAKA and Akio SAGARA \\ National Institute for Fusion Science, 322-6 Toki, Gifu 509-5292, Japan
}

(Received 7 December 2012 / Accepted 15 April 2013)

\begin{abstract}
The surface of a 316 stainless steel (316SS) specimen was nitrided by an electrochemical treatment in molten fluoride salt. Its hydrogen permeability was evaluated and compared with that of bare 316SS at temperature from $450^{\circ} \mathrm{C}$ to $650^{\circ} \mathrm{C}$. When it was exposed to hydrogen pressure of $1.0 \mathrm{kPa}$ from $450^{\circ} \mathrm{C}$ to $650^{\circ} \mathrm{C}$, its permeability was $7.2 \times 10^{-11}$ to $6.4 \times 10^{-12} \mathrm{~mol} / \mathrm{sec} . \mathrm{m} \cdot \mathrm{Pa}^{1 / 2}$. The permeation flux was increased with temperature and the permeability is deviated from Sieverts' law around $450^{\circ} \mathrm{C}$. It followed Sieverts' law and was similar to that of bare 316SS at elevated temperatures. This result suggested the surface nitriding increases solubility at low temperatures around $450^{\circ} \mathrm{C}$.
\end{abstract}

(C) 2013 The Japan Society of Plasma Science and Nuclear Fusion Research

Keywords: blanket system, molten fluoride salt, structural material, electrochemical nitriding, hydrogen permeability control

DOI: $10.1585 /$ pfr.8.2405076

\section{Introduction}

Molten fluoride salts such as Flibe and Flinak have high potential for liquid blanket in nuclear fusion reactors [1]. Fluoride salt, however, corrodes structural materials such as steel due to high operation temperature over $500^{\circ} \mathrm{C}$. Therefore, the structural materials for the blanket require compatibility with fluoride salt. At the same time, inventory of the bred tritium inside the blanket system must be strictly controlled. Unanticipated tritium leakage from the blanket system should be prevented for safety and fuel economy. And effective extraction technology is also requisite for tritium recovering.

Compatibility with fluoride salt on several materials was examined and it was revealed that nitride has compatibility with fluoride salt [2]. And surface nitriding technique of metal surface based on electrochemistry in molten fluoride salt was applied [3]. The surface nitride layer, which consists of graded composition structure, is expected to be more robust than ceramics coating films against defects such as peeling, cracks and pinholes. In terms of in-situ maintenance of structural components in contact with molten Flibe or Flinak in the blanket system, nitriding treatment in molten salt itself such as ion nitriding and radical nitriding could be more advantageous than other vapour phase nitriding treatments.

Tritium permeability should be measured in nuclear facilities. A prospect about it is provided by measurement of hydrogen permeability. Before tritium permeability measurement, hydrogen permeability should be measured. This article represents modification of nitride on 316 stainless steel (316SS) surface and its hydrogen permeability. Hydrogen permeability of the nitrided stainless

author'se-mail: watanabe.takashi@nifs.ac.jp

$\left.{ }^{*}\right)$ This article is based on the presentation at the $22 \mathrm{nd}$ International Toki Conference (ITC22). steel was measured by the build up process.

\section{Experimental}

Figure 1 demonstrates a reactor for electrochemical nitriding. 316SS specimens were nitrided as described in previous report [3].

For hydrogen permeability measurement, coin shape specimens $($ diameter $=12.0 \mathrm{~mm}$, thickness $=1.0 \mathrm{~mm})$ were treated by potentiostatic treatment at $600^{\circ} \mathrm{C}$ at $1.0 \mathrm{~V}$ versus $\mathrm{Li}^{+} / \mathrm{Li}$ in $\mathrm{LiF}-\mathrm{KF}-\mathrm{Li}_{3} \mathrm{~N}$ (mixture ratio of $49 \mathrm{~mol} \% \mathrm{LiF}$,

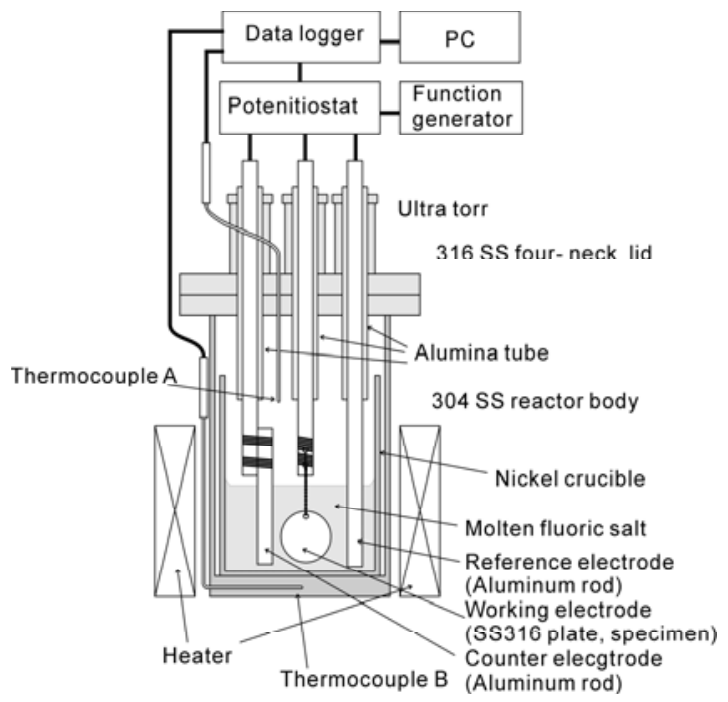

Fig. 1 Schematism of equipment for electrochemical nitriding. Molten fluoride salt was filled in the crucible at $600^{\circ} \mathrm{C}$. Working electrode binned a 316SS specimen, aluminum counter electrode and aluminum reference electrode were immersed. $\mathrm{Li}_{3} \mathrm{~N}$ was added to fluoride salt as a nitrogen source. The surface of the specimen was nitrided at $1.0 \mathrm{~V}$ versus $\mathrm{Li}^{+} / \mathrm{Li}$ for $240 \mathrm{~min}$. 


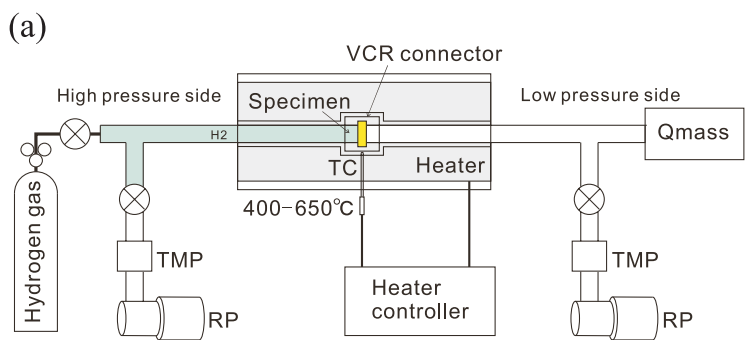

(b)

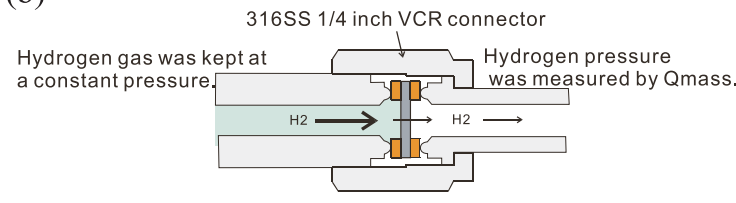

Fig. 2 Schematism of measurement apparatus for hydrogen permeation. (a) Overall view. The specimen divides into high pressure side and low pressure side and works as a separator. (b) Sample holder. The specimen was held in VCR connector. After evacuating to $10^{-5} \mathrm{~Pa}$ in the both sides, hydrogen gas was filled at a constant pressure in the high pressure side. Hydrogen flux through the specimen was measured by Qmass.

$49 \mathrm{~mol} \% \mathrm{KF}$ and $2.0 \mathrm{~mol}^{2} \mathrm{Li}_{3} \mathrm{~N}$ ). A working electrode with a $316 \mathrm{SS}$ specimen, aluminum counter electrode and aluminum reference electrode were immersed. After the nitriding treatment, the specimen was washed in water to remove the fluoride salt.

The specimens were characterized by scanning electron microscopy (SEM), Energy Dispersive X-ray spectrometry (EDX), electron probe micro analyzer (EPMA), $\mathrm{X}$-ray photoelectron spectroscopy (XPS) and X-ray diffraction (XRD) about surface structure and chemical components.

Steady-state hydrogen permeability was evaluated by a build up method at a constant temperature in the range between 450 and $650^{\circ} \mathrm{C}$. Figure 2 shows measurement apparatus for hydrogen permeation. A specimen was held in a VCR connector set. The specimen separates the system into high pressure side and low pressure side. After evacuating to $10^{-5} \mathrm{~Pa}$ in the both sides, hydrogen gas was filled at a constant pressure ranging from $1.0 \mathrm{kPa}$ to $40 \mathrm{kPa}$ in the high pressure side, i.e. the upstream side. The hydrogen flux through the specimen was measured by quadrupole mass spectrometry (Q-mass)

\section{Results and Discussion}

\subsection{Nitrided surface of $316 \mathrm{SS}$}

Figure 3 shows XPS typical spectra of specimen. 316SS mainly consists of iron, chromium, and nickel. Figure 3 (a) indicates that nitrogen was introduced by the electrochemical treatment. Figure 3 (b) indicates that the chemical state of chromium changed from metallic to tervalent. These results suggest that chromium nitride was formed. On the other hand, the iron state and the nickel (a)

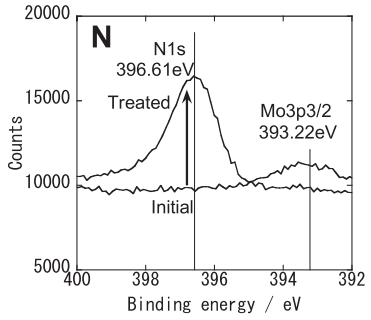

(b)

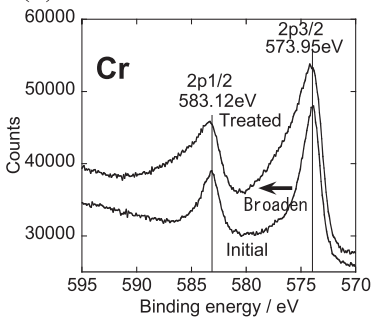

(d)



Fig. 3 XPS spectra. (a) nitrogen, (b) chromium, (c) iron, and (d) nickel. The electrochemical treatment intruded nitrogen at the surface of 316 SS specimen. Chemical state of chromium changed from metallic to trivalent. Chemical state of iron and nickel did not change [3].

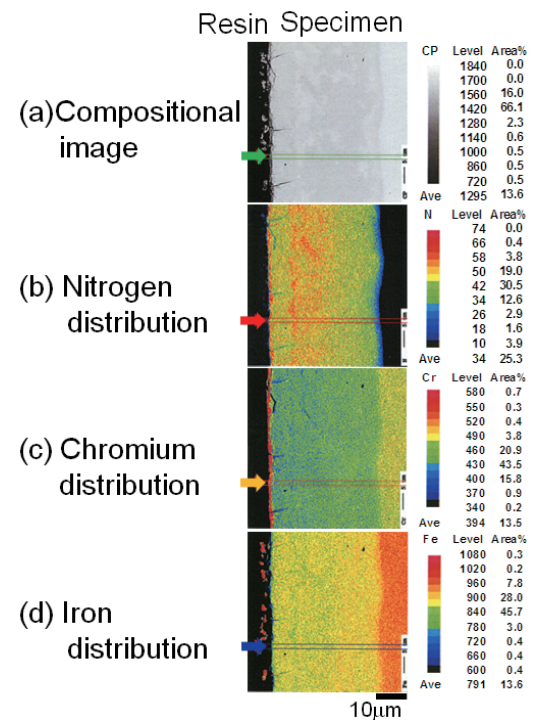

Fig. 4 EPMA images of specimen cross section. (a) SEM image corresponding to EPMA mapping images, (b) nitrogen distribution, (c) chromium distribution, (d) iron distribution [3].

state did not change as shown in Figs. 3 (c) and 3 (d).

Figure 4 shows EPMA mapping images of a specimen cross section. Figure 4 (a) demonstrates SEM image. Figure 4 (b) demonstrates that the electrochemical treatment for $100 \mathrm{~min}$ introduced nitrogen into the depth of about $35 \mu \mathrm{m}$. As shown in Figs. 4 (c) and 4 (d), Concentration of iron and chromium decreased with nitrogen introduction.

Figure 5 shows the line profiles from the EPMA mapping images shown in Figs. 4. The arrows and lines in Figs. 4 indicate analyzed position. The electrochemical 


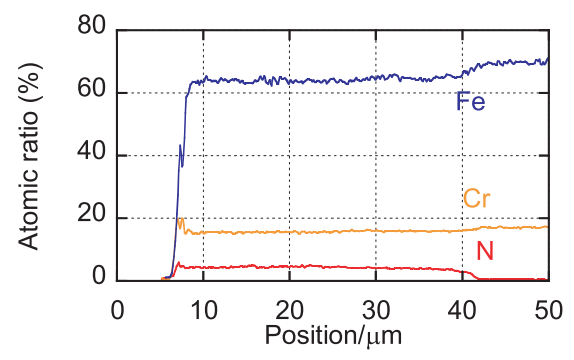

Fig. 5 Line profiles from the EPMA mapping images demonstrated in Figs. 4. The arrows and lines in Figs. 4 indicate analyzed position [3].

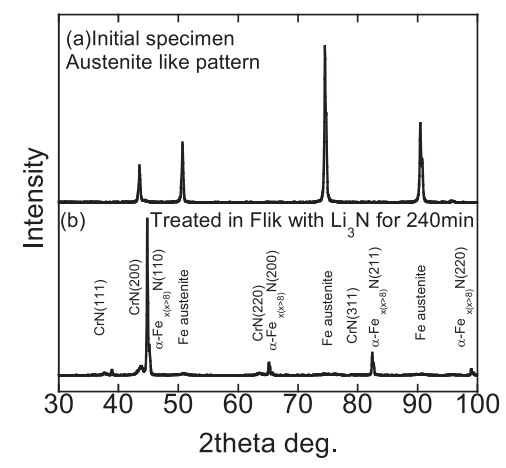

Fig. 6 XRD patterns of 316 specimens. (a) Initial 316SS specimen. It corresponds to bare 316SS. (b) Specimen treated for $240 \mathrm{~min}$. The initial specimen demonstrated austenite like pattern; the nitrided specimen demonstrated chromium nitride and $\alpha-\mathrm{Fe}_{\mathrm{x}(\mathrm{x}>8)} \mathrm{N}$.

treatment for $100 \mathrm{~min}$ also introduced nitrogen into the depth of about $35 \mu \mathrm{m}$.

Figure 6 shows XRD typical patterns of the specimens. Figure 6 (a) shows the pattern of initial specimen. It indicated fcc phase similar to that of austenite steel. Figure 6 (b) shows the nitrided specimen. It indicated that chromium nitride, $\mathrm{CrN}$, was formed near the surface.

Since the XRD pattern also includes bct crystal phase pattern of iron, it was revealed that the nitrogen introduction changed drastically composition and crystal structure. Iron nitride $\alpha-\mathrm{Fe}_{\mathrm{x}(\mathrm{x}>8)} \mathrm{N}$ was also formed as a solid solution where nitrogen atoms are inserted between iron atoms. It was formed from the surface to a depth of $35 \mu \mathrm{m}$ as an inside diffusion layer. As described all of above, it was revealed that the electrochemical treatment formed chromium nitride at the surface of 316SS.

Nitrogen retention was also confirmed after hydrogen permeability measurement by EDX. This means that introduction of hydrogen to the specimen did not remove nitrogen from it.

\subsection{Hydrogen permeability of nitrided 316SS}

Hydrogen permeation was measured using the specimens nitrided for $240 \mathrm{~min}$ and bare $316 \mathrm{SS}$ specimens. Fig-

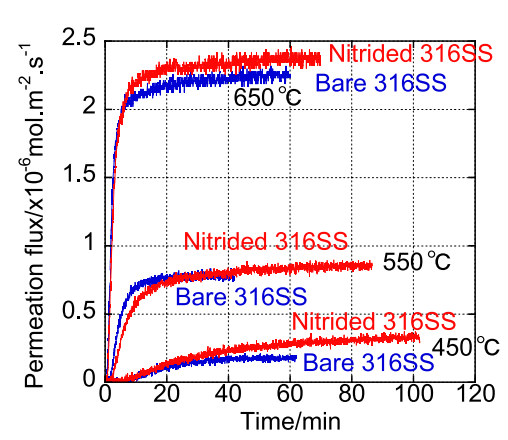

Fig. 7 Permeation behaviors of bare 316SS and nitrided 316SS specimens from 450 to $650^{\circ} \mathrm{C}$. Hydrogen pressure at $1.0 \mathrm{kPa}$ in the high pressure side was added at $0.0 \mathrm{~min}$.

ure 7 shows those hydrogen permeation behavior after hydrogen pressure was added in the high pressure side at 0.0 min. Permeation flux of the nitrided 316SS specimen was twice as much as that of the bare 316SS specimen at low temperature around $450^{\circ} \mathrm{C}$. Permeation through the nitrided 316SS rose up more slowly to reach steady flux than that of bare 316SS. Nitriding could increase solubility and simultaneously limit diffusion, which consequently increased hydrogen permeability. However, these differences between bare and nitrided 316SS specimens diminished with rising temperature.

Permeation was assumed as follows:

$$
J=\frac{P p^{n}}{d}
$$

Where $J$ is the permeation flux, $P$ is permeability; $p$ is hydrogen pressure introduced into the high pressure side, and $d$ is the thickness of the specimen. The exponent $n$ relates to permeation regime. Diffusion limits permeation when $n=0.5$, following Sieverts' law, while surface recombination limits that when $n=1$ [4]. Assuming exponent $n=$ 0.5 , permeability is

$$
\begin{aligned}
P & =\frac{J d}{\sqrt{p}}, \\
& =P_{0} \exp \left(-\frac{E_{\mathrm{P}}}{\mathrm{R} T}\right),
\end{aligned}
$$

where $E_{\mathrm{P}}$ is activation energy of permeation, $\mathrm{R}$ is a gas constant and $T$ is absolute temperature. Figure 8 shows hydrogen permeability of bare 316SS and nitrided 316SS from $450^{\circ} \mathrm{C}$ to $650^{\circ} \mathrm{C}$. Bare $316 \mathrm{SS}$ specimen has permeation behavior consistent with result evaluated by T. Shiraishi et al. [5]. The permeability of the nitrided 316SS specimen seems to have linearity over $500^{\circ} \mathrm{C}$. However, it was slightly larger than that of the bare 316SS specimen. The permeability increase was more remarkable under $500^{\circ} \mathrm{C}$. The activation energy of the nitrided specimen in diffusion process was about $6.7 \mathrm{~J} / \mathrm{mol}$ in the temperature range over $500^{\circ} \mathrm{C}$. It is consistent with that of bare $316 \mathrm{SS}$.

Figure 9 shows hydrogen pressure dependence of permeation flux in temperature range from $450^{\circ} \mathrm{C}$ to $650^{\circ} \mathrm{C}$. 


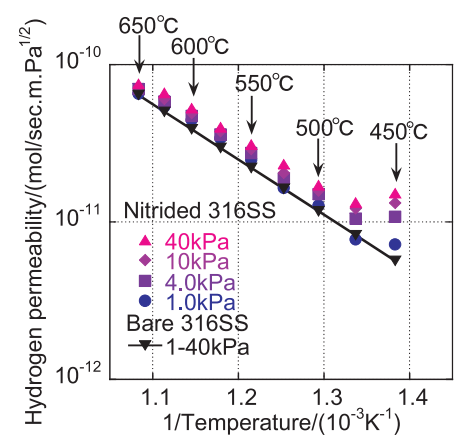

Fig. 8 Hydrogen permeability comparison between bare 316SS and nitrided $316 \mathrm{SS}$.

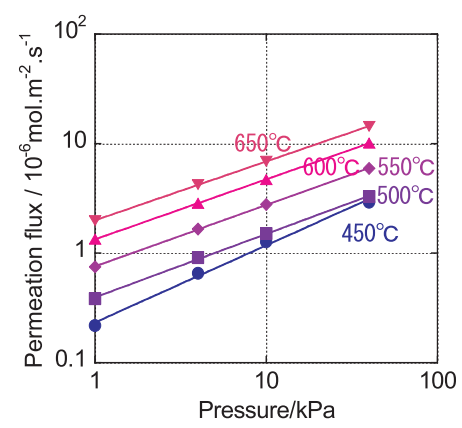

Fig. 9 Hydrogen pressure dependence of permeation flux in temperature range from $450^{\circ} \mathrm{C}$ to $650^{\circ} \mathrm{C}$.

Gradient of the lines corresponds to exponent $n$. It was 0.75 at $450^{\circ} \mathrm{C}$ and approached to 0.55 at elevated temperatures. Permeation flux looks to be proportional to the square root of pressure over $500^{\circ} \mathrm{C}$. While permeability seems to be limited by diffusion process, i.e., ruled by Sieverts' law over $500^{\circ} \mathrm{C}$, it apparently deviates from the law around $450^{\circ} \mathrm{C}$.

Figure 10 shows this deviation behavior. It demonstrates temperature dependence of exponent $n$.

While exponent $n$ of the bare $316 \mathrm{SS}$ was about 0.55 , that of the nitrided $316 \mathrm{SS}$ at $450^{\circ} \mathrm{C}$ was 0.70 and swerved from $n=0.5$, i.e. Sieverts' law. This result suggests that the nitrided layer affects on permeation of nitrided 316SS.

According to the permeability behavior described above, it looks natural to think that nitrogen might be removed by hydrogen exposure. EDX measurement, however, demonstrated nitrogen retention after hydrogen permeability measurement. Several reports have demonstrated nitrides as a hydrogen diffusion barrier [6-10]. The measured results, however, suggest that the nitride layer affects on hydrogen solubility at the surface and also increased it at the temperature below $500^{\circ} \mathrm{C}$. Alternatively, although formation of $\mathrm{CrN}$ and $\alpha-\mathrm{Fe}_{\mathrm{x}(\mathrm{x}>8)} \mathrm{N}$ was confirmed,

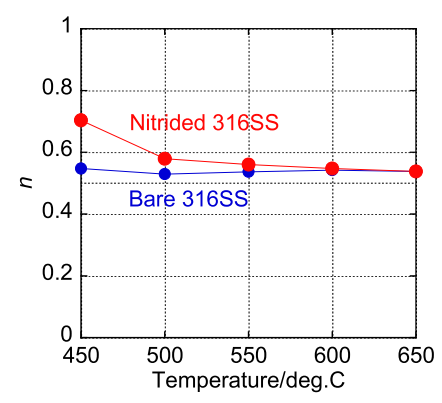

Fig. 10 Temperature dependence of exponent $n$. It demonstrates that the nitrided 316SS deviated from Sieverts' law under $500^{\circ} \mathrm{C}$.

the amount of these nitrides might not be enough to reduce permeability. If more nitrogen was introduced and denser nitride layer including $\mathrm{Fe}_{2} \mathrm{~N}$ was formed, the layer might reduce permeability.

Even if considering these, it could not explain solubility increase around $450^{\circ} \mathrm{C}$. Hereafter, for analysis of the permeation behavior and for hydrogen permeation controlling, some surface processes such as catalytic process or surface area expansion might need to be considered together with more data.

\section{Conclusions}

316SS was electrochemically nitrided in molten fluoride salt. Its hydrogen permeability was determined and compared with that of bare $316 \mathrm{SS}$ from $450^{\circ} \mathrm{C}$ to $650^{\circ} \mathrm{C}$. When it was exposed to hydrogen pressure of $1.0 \mathrm{kPa}$ from $450^{\circ} \mathrm{C}$ to $650^{\circ} \mathrm{C}$, its permeability was $7.2 \times 10^{-11}$ to $6.4 \times 10^{-12} \mathrm{~mol} / \mathrm{sec} \cdot \mathrm{m} \cdot \mathrm{Pa}^{1 / 2}$. The permeation flux was larger than that of the bare $316 \mathrm{SS}$ and the permeability behavior deviated from Sieverts' law around $450^{\circ} \mathrm{C}$. Permeation behavior of the nitrided 316SS approaches to that of the bare $316 \mathrm{SS}$ with increasing temperature over $450^{\circ} \mathrm{C}$. This result suggested the surface nitriding increases solubility at low temperature around $450^{\circ} \mathrm{C}$.

[1] A. Sagara et al., Nucl. Fusion 45, 258 (2005).

[2] T. Watanabe et al., J. Plasma Fusion Res. Series 9, 342 (2010).

[3] T. Watanabe et al., Electrochimica Acta 58, 681 (2011).

[4] K.S. Pisarev et al., J. Nucl. Mater. 160, 117 (188).

[5] T. Shiraishi et al., J. Nucl. Mater. 273, 60 (1999).

[6] C. Shan et al., J. Nucl. Mater. 191-194, 221 (1992).

[7] Z. Yao et al., J. Nucl. Mater. 283-287, 1287 (2000).

[8] A.M. Brass et al., J. Mater. Sci. 24, 1693 (1989).

[9] Z. Wolarek et al., Acta Materialia 52, 2637 (2004).

[10] Z. Wolarek et al., Acta Materialia 54, 1525 (2006). 